\title{
GEOSPATIAL ECOLOGICAL FOREST CORRIDOR MODELLING IN THE MOUNT LANTOY KEY BIODIVERSITY AREA
}

\author{
I. P. Quijano ${ }^{1}$, M. J. L. Flores ${ }^{1,2}$, A. B. Malaki ${ }^{3,4}$ \\ ${ }^{1}$ Center for Environmental Informatics, University of the Philippines Cebu, Philippines - (ilquijano, mlflores2)@up.edu.ph \\ ${ }^{2}$ Department of Biology and Environmental Science, College of Science, University of the Philippines Cebu- mlflores2@up.edu.ph \\ ${ }^{3}$ College of Forestry, Cebu Technological University Argao Campus, Cebu, Philippines - archlam68@gmail.com \\ ${ }^{4}$ Cebu BioMes Project, Cebu Technological University Argao Campus, Cebu, Philippines
}

\section{Commission IV}

KEY WORDS: Ecological Corridors, Black Shama, Environmental Informatics, Spatial Ecology

\begin{abstract}
:
In biodiversity conservation, ecological corridors are assumed to increase landscape-level connectivity and to enhance the viability of otherwise isolated wildlife populations. Mapping these corridors serves as a feasible method to support forest management efforts in pinpointing areas to give special attention to. Here, we assess the current forest presence in the 3,000 hectare Mt. Lantoy, Key Biodiversity Area in Argao, Cebu and present potential forest corridors that could enhance the canopy cover of the current protected area. We present a method to map the potential corridors through the identification of the forest patches obtained from the global forest cover dataset and the creation of a species distribution model for the black shama, an endemic bird species in Cebu island and a great biodiversity indicator for the area. Our ecological corridors were acquired through the sum of the cost distance rasters obtained from the weighted overlay and cost surface tools of the black shama habitat suitability model. With the obtained corridors from the study, four potential forest corridors/ extensions were identified connecting five different forest patches. These corridors have areas that range from $0.47-2.17$ square kilometers, with a potential to increase the forest cover in the KBA to more than $33 \%$ after corridor modelling.
\end{abstract}

\section{INTRODUCTION}

All the tropical forest ecosystems combined host at least twothirds of the total terrestrial biodiversity in the world. Unfortunately, the last century has marked an astonishingly rapid decline regarding the extent of tropical forests around the globe (Gardner et al., 2009). It has been estimated that 350 million hectares have been deforested and another 500 million hectares of tropical forest have been degraded. The consequences of this are the loss of ecological services, which include the loss of biodiversity and watershed protection, the loss of many goods, like timber and non-timber forest products and the loss of means of existence for tribes inhabiting the forest (Lamb et al, 2005).

In response to this, several actions have been undertaken to reduce the impact of forest degradation. The first response has been to expand protected areas to help protect the remaining biodiversity. However, since the forest provides an important source of income for a huge part of the population, expanding protected areas which were previously a source of income for the population cannot be implemented without boundaries. Another response has been to improve the use of abandoned land by means of agriculture, so there is less need to deforest new land for agriculture. As a last resort, some actions have been undertaken in the form of reforestation. Unfortunately, even with the previous mentioned actions, there still has been a gradual decline, simplification and homogenization of some of the world's most biologically diverse landscapes (Lamb et al, 2005).

Most of the degraded landscapes have turned into a mosaic of land, with patches of intact residual forest, productive agricultural, as well as degraded lands. Analyzing the patch dynamics has proven to be a valuable tool to predict changes in the biodiversity of an ecosystem. External conditions including climate change and habitat fragmentation will change the internal dynamics of patches (Gardner et al, 2009). To detect these changes, geographic information systems (GIS) can be used to map data in order to investigate relationships and changes among patches. This data can consist of elevation data, locations of animal observations or boundaries of habitat areas (Green \& Cousins, 1997).

\subsection{Study Area}

The study area chosen was the Mt. Lantoy key biodiversity area (KBA) in the municipality of Argao, South Cebu (Fig. 1). Aside from being a recognized KBA, Mt. Lantoy is also considered a an important bird area. Species found in the vicinity include numerous native and endemic flora and fauna such as 26 threatened endemic tree species and the endangered black shama (Copsychus cebuensis).

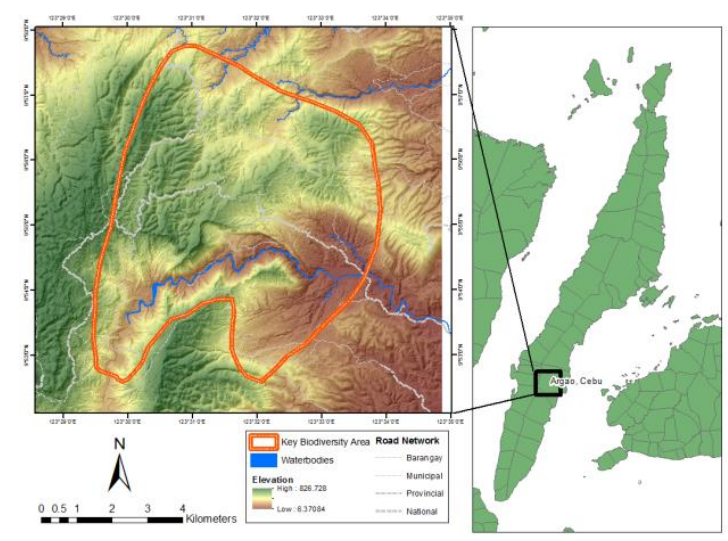

Figure 1. Study Site: Mt. Lantoy Key Biodiversity Area 


\section{RELATED LITERATURE}

In the process of protecting wildlife, national parks and conservation reserves are established. The establishment of ecological corridors between nature reserves can connect isolated habitats and reduce the rate of species extinction. The paths for wildlife movement can be defined as ecological corridors (Santos et al., 2018). There are various benefits of building ecological corridors such as, protecting the diversity of species, diffusing the animals (Merriam \& Lanoue, 1990), increasing the exchange of genes, and reducing the risk of extinction (Kupfer \& Malanson, 1993). On the other hand, an ecological corridor could be a channel for the spread of harmful organisms, which is a disadvantage to the survival and spread of the target animals for protection (Simberloff \& Cox, 1987).

In studies on the identification of the ecological corridor, the theories of island biology and meta-population have usually been suggested as the theoretical foundation. The structure of the ecological corridor refers to the combination of number, background, width, degree of connectivity, composition, and characteristics of key points (Zhu et al., 2005). Forman (1995) suggested that corridors can be the habitat of wildlife and can act as a channel, source, sink, obstruction, and filter for biological movement (Forman,1995).

One of the earliest practical recommendations for land use to arise from studies of habitat fragmentation was for fragments to be linked by a corridor of similar suitable habitat to have greater conservation value (Diamond, 1975). This initial recommendation was based entirely on theoretical considerations, primarily stemming from island biogeographic theory. Subsequently, protection or provision of continuous corridors of habitat to link isolates such as nature reserves, woodlands or patches of old-growth forest have been widely recommended as conservation measures to counter the impacts of habitat reduction and fragmentation.

Why has there been such widespread interest in corridors as a conservation measure? First, the concept is intuitively appealing as a practical measure that responds directly to the isolating effects of habitat fragmentation (i.e. if isolation of habitats is the problem, then linking them together is the solution). It is also a visible solution to a visible problem (Bennett, 1999). Habitat corridors are a visible sign of efforts to 'mend' the fragmented landscape like 'bandages for a wounded natural landscape' (Saunders \& Hobbs, 1991). Second, the concept of providing linkages for conservation can be applied at several scales which is relevant both to local conservation efforts and to regional or national strategies. In local environments, habitat links can be protected, managed or restored at the level at which individuals or community groups are able to carry out conservation works. It is feasible for local communities to actually manage linkages in their local environment and see visible environmental change as a result (Bennett, 1999).

At regional scales, connecting large core areas of wildlife habitat requires corridors - land managed for its function as routes for wildlife movement and dispersal (Saunders \& Hobbs, 1991). The notion of connective habitat corridors implies a system of corridors and the core areas of habitat which they serve to link. Conceptual models of core areas, movement corridors, and buffer zones have been proposed by several workers (Saunders \& Hobbs, 1991; Noss et al., 1996; O'Connell \& Noss, 1992) as frameworks for long-term regional scale conservation of wildlife.
In order to contribute to defining a scientific framework for linkage zone assessment (or corridor analysis) an independent effort to delineate wildlife corridors according to the conservation biology model (cores, corridors, buffers) at regional scale in a specific geographic area was reported by the researchers. Using Geographical Information System (GIS), a conceptual model of core areas, movement corridors, and buffer zones can be created.

Wildlife does not recognize the boundaries created by human activity. The creation of highways across the habitats of large, roaming mammals often results in significant deaths such as when bears attempt to cross highways which pass through their ranges. Specific crossing points can be built as part of a highway project, but where should wildlife corridors be placed to maximize their value? In a study to find the best approach to creating linkages between areas of the range of black bears where the Trans-Canada Highway passes through Banff National Park, Alberta, Canada (Clevenger \& Et al., 2002), GIS played a key part. Suitability maps indicating the areas that are most likely to be selected by bears for crossing points were developed with GIS software. Several sources of data on bear movements were used to create and compare models to predict the most likely linkage points that would be used by bears, to minimize both construction costs and road-kill. This kind of successful research highlights the advantages of GIS models over the time-consuming and expensive process of collecting data in case-by-case situations.

Conservation biology places a major emphasis on the preservation of biodiversity. This means that data on the distribution of endangered species and of suitable habitats for such species is of utmost concern to biologists working in the field. Like animals, plants also do not recognize man-made boundaries or borders. In a study of endangered tree species in Egypt (Salem, 2003), GIS systems were used for effective map overlay of the ranges of endangered plant and of habitat areas including those already declared as reserves and those still proposed at the time of the study. This research addresses a critical issue in biodiversity conservation, the ability to match conservation areas with the actual distribution of a wide variety of species within a target area. By using these GIS maps, botanists and wildlife managers can visualize and present suitable data to optimize the boundaries of reserves during their creation. This can achieve the highest rate of biodiversity preservation in the complex negotiations necessary to balance social and economic needs with habitat and species conservation.

Currently, fragmentation has become a global issue, and anthropogenic activities are considered as the main cause for the loss of connectivity between different habitats (Vitousek et al., 1997). With the rapid development of the economy, the construction of roads is one of the main reasons for biodiversity loss, and it is also a barrier for wildlife movements. The importance of roads in socio-economic development includes connecting geographical space and human socio-economic activities, promoting local economic development, and growing social wealth. However, roads also bring about various adverse effects on ecosystems and natural landscapes (Liu \& Et al., 2013).

Construction of lines and strips (e.g., railways and expressways create 'road-effect zones' that affect land use, soil stability, vegetation, landscape pattern, habitat or landscape connectivity, ecological risk, animal migration, wildlife corridor, and 
ecosystems. They can serve as obstacles to separate different parts of landscape, acting as a barrier and filter for wildlife (Forman \& Alexander, 1998; Pan \& Liu, 2015).

\subsection{Black Shama}

One of the species that is negatively affected by these rapid changes in the landscape is the black shama. The black shama (Copsychus cebuensis) is endemic to Cebu Island. Its habitat is primary forest and the dense undergrowth of secondary habits along valleys that have a high percentage of canopy cover. The black shama has also been found in scrub and cut-over forests, bamboo groves and plantations. However, according to Jakosalem and Paguntalan (2007) the black shama prefers forest habitats but due to the degradation of these, it is forced to inhabit degraded habitats as well (Malaki et al., 2018).

The black shama became an endangered species due to its small range and population size both of which are continuously declining. The degradation processes posed by human activities including settlement, shifting cultivation, firewood gathering, illegal cutting of trees for house construction, land use conversion, and habitat clearance for mining led to severe fragmentation of the black shama's habitat. This puts extreme pressure on the few remaining subpopulations that are still found in Cebu Island (Malaki et al., 2018).

An important consideration in restoration efforts for endangered species is to maintain a high genetic diversity. A significant level of genetic diversity should be maintained in (sub)populations since it is the basis of the evolutionary potential of species to respond to environmental changes. As the remaining black shama subpopulation inhabit different patches, they became divided to different breeding groups. Thus, an important consideration is to (re)connect these subpopulations to maintain a certain level of genetic diversity (Toro \& Caballero, 2005).

\section{PROPOSED METHOD}

The elevation raster used for this study was a digital elevation model from the Phil-LiDAR project, the slope raster and feature vectors were derived from this dataset. The forest cover and the tree density rasters were derived from Hansen et al.'s (2018) global forest change dataset from the Google earth engine database. The bioclimatic variables used for the ecological niche model was obtained from the worldclim website, an open source repository for climate bioclimatic variables. Black shama distribution shapefiles were derived from gathered field observation data from Malaki et al. (2018).

\subsection{Identifying Habitat Patches}

Because available forest cover datasets over-exaggerated the forest covers and encompassed forest zones rather than actual canopy covers the following method was used to identify the study's forest patches.

Habitat patches were identified using the tree density raster from the global forest change dataset acquired from Google Earth Engine (Hansen et al., 2013). Patches with at least 60\% canopy cover were extracted from the dataset and thus serves as the forest patches for the study (Fig. 2).

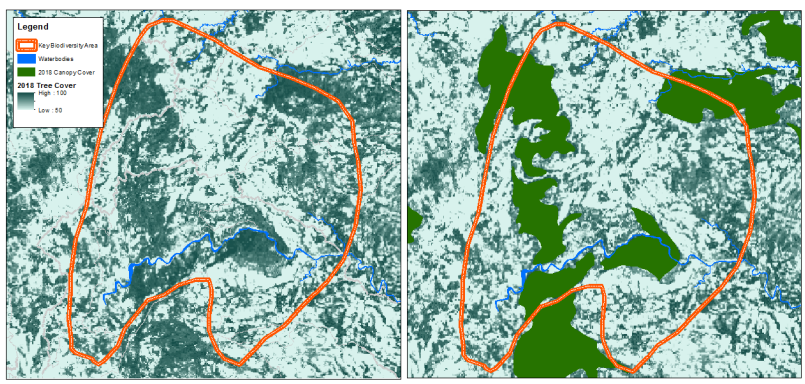

Figure 2. Map (A) shows the tree cover dataset used and Map (B) shows the extracted forest fragments

In the interest of creating forest corridors for important species like the black shama, we identified source fragments as those with known shama populations taken from Malaki and colleagues' (2018) study dataset and those without data as destination fragments (Fig. 3).

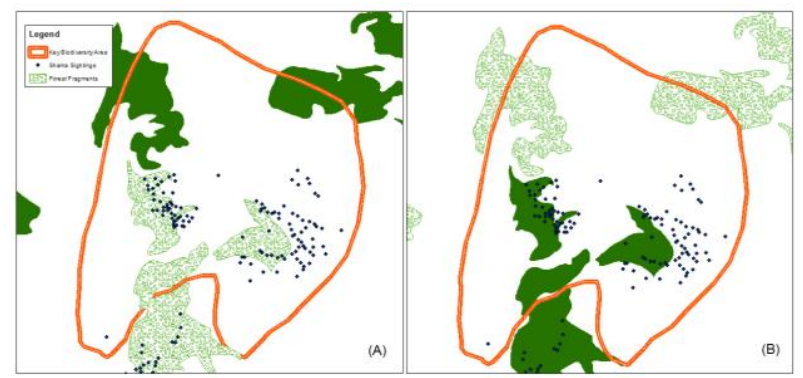

Figure 3. Map (A) shows the source forest fragments in light green while Map (B) shows the destination forest fragments.

\subsection{Black Shama}

The black shama (Copsychus cebuensis), an endemic interior bird species preferring intact forests (Labrador \& Patindol, 2006), is considered as the primary indicator species for the study. Birds serve as good environmental indicators because they are easy to detect and are easily observed. If a habitat does not fulfill their habitat requirements they take flight and find better habitats.

The black shama, a specialist species only found in select forests in Cebu island is considered highly sensitive to habitat change, evidenced through its dwindling number and its endangered status parallel to the continued degradation of forest habitats in the province. Furthermore, canopy cover has shown to have a significant positive correlation to black shama population densities (Malaki et al., 2018), making them great indicators to help model possible forest corridors.

For this reason, this study utilizes black shama occurrence data from Malaki and colleagues (2018) to create the habitat suitability analysis and climate change adaptation aspects.

\subsection{Ecological Niche Modeling}

In coming up with the black shama's ecological niche, A species distribution modeling package in the $\mathrm{R}$ open source environment was used. Data pre-processing of the worldclim climate data was done through clipping, reclassifying and projecting the needed materials and more importantly, converting these environmental layers from Rasters to ASCII.

The model was created through the prediction of a species' potential distribution by estimating the fundamental ecological 
niche of a species given the contribution of the climate variables. The niche model used for the study is shown in Figure 4

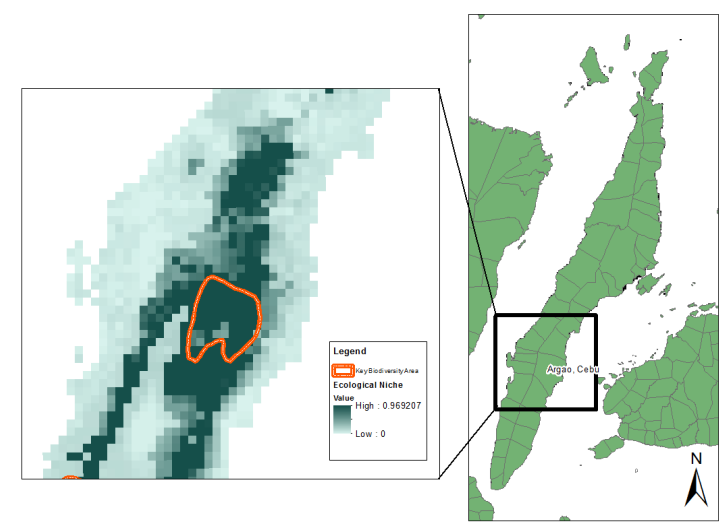

Figure 4. (A) Black shama ecological niche model

\subsection{Cost Surface}

For the analysis, the value of one was given to the flattest slope and ten for the steepest ones. In the case of the elevation raster, one (1) was given to 100 to 1000 MASL, and two (2) for higher altitudes with respect to Malaki et al.'s (2018) study citing Philippine forest bird sightings getting rarer with elevations greater than 1000MASL.

One (1) was given for areas closest to the water bodies and ten (10) for the farthest. The opposite score was given for areas in the vicinity of roads and densely populated areas, ten for areas closer or directly in human interference and one farthest from it.

The ecological niche layer was scored one for those with higher black shama predictions and ten for the other end of the spectrum. Similarly, the tree density layer scores one for denser tree canopies and ten for those with no canopy cover.

Weighted Overlay: For the weighted overlay, all layer scores were added assuming equal weight for all input layers (Fig. 5).

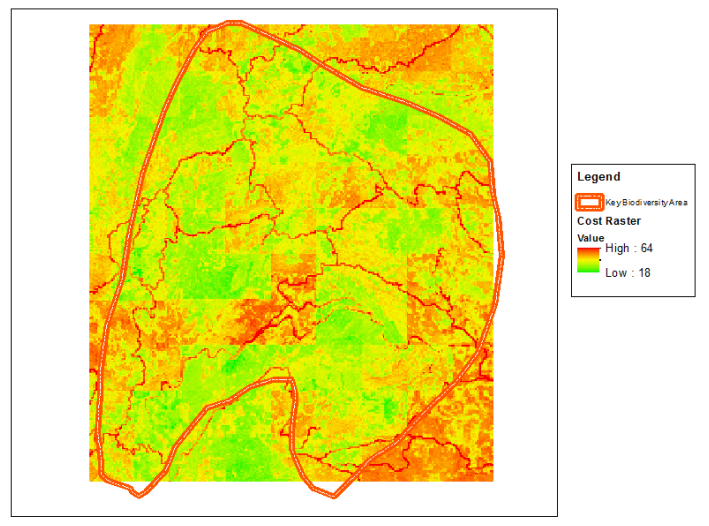

Figure 5. Cost Raster visualizes the cost in each cell for connecting forest fragments in Mt. Lantoy KBA

\subsection{Identifying Potential Ecological Corridors}

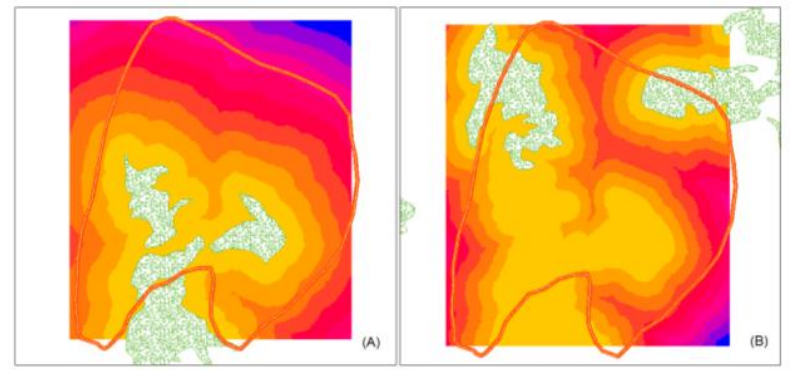

Figure 6. (A) Source Cost Distance Raster and (B) Destination Cost Distance Raster

The ecological corridors were acquired through the sum of two cost distance rasters obtained from the (1) source and (2) destination forest patches. These cost distance rasters compute the cumulative cost of travel for each cell away from its neighboring ones. Figure 7 shows the computed cost path.

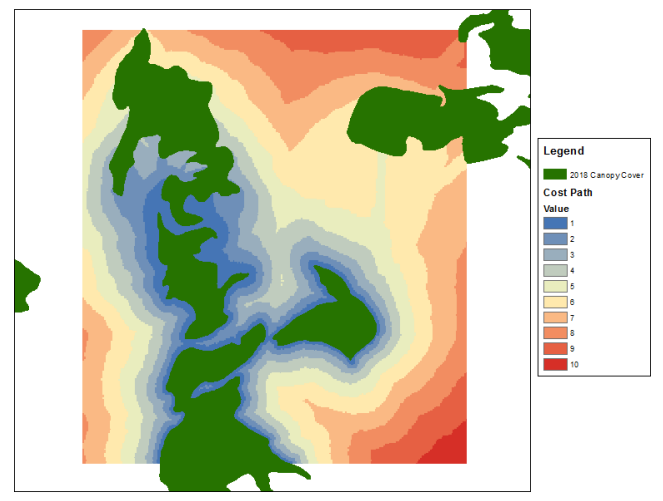

Figure 7. Cost path raster in linking different forest fragments

Ultimately, our ecological corridors were produced by selecting the least cost path from different connectivity networks in our cost path raster. Figure 8 shows the computed least cost paths for our fragments on the left (A) and the least cost connectivity path to join all forest fragments on the right (B).

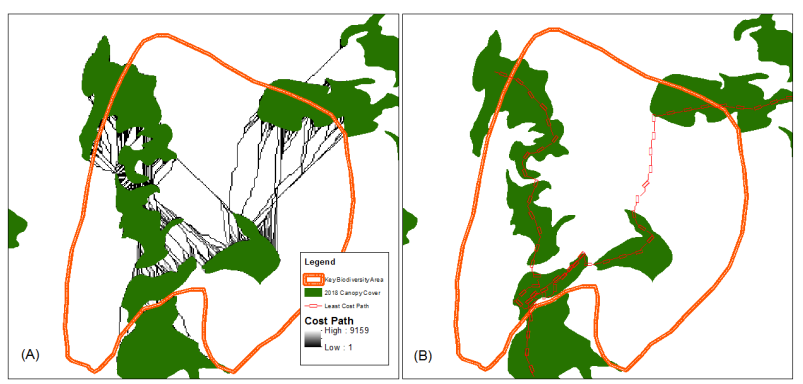

Figure 8. (A) Least cost paths and (B) Cost Connectivity 


\section{DISCUSSION AND CONCLUSIONS}

\subsection{Results and Discussion}

The cost distance output of the study's analysis identifies concentrated areas of low cost possible forest corridors and forest extensions suitable for black shama habitat. Figure 9 and Table 1 shows the four computed corridors for Mt. Lantoy $\mathrm{KBA}$, the largest of the corridors being 2.17 square kilometres linking a source fragment to a destination fragment.

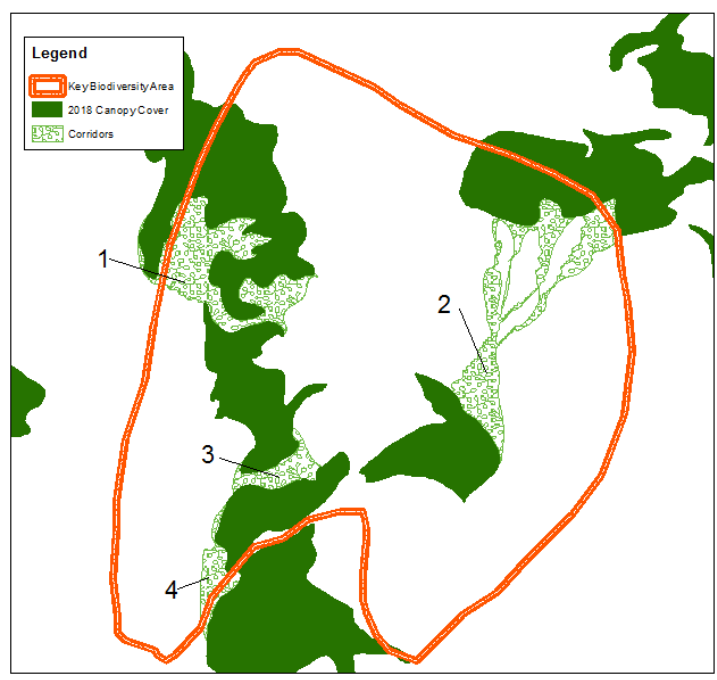

Figure 9. Computed ecological corridors

\begin{tabular}{|r|r|}
\hline ID & \multicolumn{1}{|c|}{ Area $\left(\mathrm{km}^{2}\right)$} \\
\hline 1 & 2.171907 \\
\hline 2 & 2.101228 \\
\hline 3 & 0.465535 \\
\hline 4 & 0.487642 \\
\hline
\end{tabular}

Table 1. Forest Corridor Patch Areas

With the obtained corridors from the study, four potential forest corridors/extensions were identified connecting five different forest patches. These corridors have areas that range from 0.47 - 2.17 square kilometers; together with the existing forest patches, this adds up the forest area inside the KBA to 15.7 square kilometers of forest.

\subsection{Conclusion, Research Limits and Future Research Directions}

This study has shown us that it is possible to create ecological corridors within the Mt. Lantoy KBA with the use of GIS data. If the modeled corridors could be managed to become a reality we would see a $33 \%$ increase in the existing 10.47738 square kilometers of forest cover in the area and in doing so, could also protect and conserve the biodiversity in our local KBAs.

Seeing as the research process is a feasible method to support forest management efforts by pinpointing areas to give special attention to; it could be a great advantage to the local communities and government units to incorporate scientific efforts like this in the creation of their land development and forest land use plans. Plans especially enhanced with climate change models could increase the adaptive capacity and therefore the usefulness of these management plans. If we see the increased forest area become a reality, we would not only see an increase in the habitats for black shama and other forest birds, but more importantly we will see an increase in the ecosystem services these forests could provide the surrounding communities and ecosystems.

This research has utilized various geospatial layers to map the local KBA, with most datasets coming from global open source repositories. If the local government units and organizations in the Philippines share their respective data, perhaps the studies created for biodiversity and ecological conservation efforts would be more comprehensive and thorough.

With detailed information regarding land use and land development plans, similar researches for forest conservation and terrestrial biodiversity protection could be tailored to fit the local community better. Future research topics in the same trajectory could be further improved by including the dynamics of the local community who conduct their livelihood and grew up with these forests. It is imperative for conservation efforts to include these communities who not only benefit from these forest ecosystems but more importantly are the ones who act as stewards in the protection of their environment and surroundings.

\section{ACKNOWLEDGEMENTS}

This research is conducted by the University of the Philippines Cebu Center for Environmental Informatics. This research is an output of Center for Environmental Informatics, Cebu Spatial Information Study subproject. We are grateful to the Department of Science and Technology (DOST) for the financial support, with the DOST Philippine Council for Industry, Energy and Emerging Technology Research and Development (PCIEERD) as the monitoring agency and the University of the Philippines Cebu as the implementing agency.

\section{REFERENCES}

Bennett, A. F. (1999). Linkages in the Landscape: the role of Corridors and Connectivity in Wildlife Conservation. Gland: IUCN.

Bonan, G. B. (2008). Forests and Climate Change: Forcings, Feedbacks, and the Climate Benefits of Forests. Science , 14441449.

Clevenger, A. P., \& Et al. (2002). GIS Generated, Expert-based Models for Identifying Wildlife Habitat Linkages and Planning Mitigation Passages. Conservation biology , 503-514.

Diamond, J. M. (1975). The Island Dilemma: Lessons of Modern biogeographic studies for the design of natural reserves. Biology Conservation .

Fick, S.E. and R.J. Hijmans, 2017. Worldclim 2: New 1-km spatial resolution climate surfaces for global land areas. International Journal of Climatology

Forman, R. T. (1995). Some general principles of landscape and regional ecology. Landscape ecology , 133-142.

Forman, R. T., \& Alexander, L. E. (1998). Roads and their major ecological effects. Annual Review of Ecology and Systematics, 207-231. 
Green, D. R., \& Cousins, S. H. (1997). Landscape Ecology And Geographical Information Systems. Londen: Taylor \& Francis. Dale, V. H., \& Et all. (2001). Climate Change and Forest Disturbance. BioScience, 723-734.

Hansen, M. C., P. V. Potapov, R. Moore, M. Hancher, S. A. Turubanova, A. Tyukavina, D. Thau, S. V. Stehman, S. J. Goetz, T. R. Loveland, A. Kommareddy, A. Egorov, L. Chini, C. O. Justice, and J. R. G. Townshend. 2013. "High-Resolution Global Maps of 21st-Century Forest Cover Change." Science 342 (15 November): 850-53. Data available on-line from: http://earthenginepartners.appspot.com/science-2013-globalforest.

Jakosalem, P. G., \& Paguntalan, L. M. (2007). Complementing local communities biodiversity conservation initiatives in Southern Cebu, Philippines. Cebu: Cebu Biodiversity Conservation Foundation, Inc.

Kupfer, J. A., \& Malanson, G. P. (1993). Structure and Composition of a Riparian Forest Edge. Physical Geography , 154-170.

Lamb, D., Erskine, P. D., \& Parrotta, J. A. (2005). Restoration of Degraded Tropical Forest Landscapes. Science, 1628-1632.

Gardner, T. A., \& Et all. . (2009). Prospects for tropical forest biodiversity in a human-modified world. Ecology Letters, 561582 .

Liu, S. L., \& Et al. (2013). Effects of road construction on regional vegetation type. Chinese Journal of Applied Ecology , $1192-1198$.

Malaki, A. B., Cruz, R. V., Bantayan, N. C., Racelis, D. A., Buot, I. E., \& Florece, L. M. (2018). Factors Affecting the Spatial Distribution of Black Shama Copsychus cebuensis Steere, 1890 in Argao Watershed Reserve. Philippine Journal of Science, 175-189.

Merriam, G., \& Lanoue, A. (1990). Corridor use by small mammals: field measurement for three experimental types of Peromyscus leucopus. Landscape Ecology, 123-131.

Noss, R. F., \& Et al. (1996). Conservation Biology and Carnivore Conservation in the Rocky Mountains. Conservation Biology , 949-963.

O'Connell, M. A., \& Noss, R. F. (1992). Private land management for biodiversity conservation. Biological Conservation , 435-450.

Pan, J. H., \& Liu, X. (2015). Assessment of landscape ecological security and optimization of landscape pattern based on spatial principal component analysis and resistance model in arid inland area: A case study of Ganzhou District, Zhangye City, Northwest China. Chinese Journal of Applied Ecology , 3126-3136.

Pardini, R., \& Et all. (2005). The role of forest structure, fragment size and corridors in maintaining small mammal abundance and diversity in an Atlantic forest landscape. Biological Conservation , 253-266.

Salem, B. B. (2003). Application of GIS to biodiversity monitoring. Journal of Arid Environments. Arid , 91-114.

Vitousek, P. M., \& Et al. (1997). Human Domination of Earth's Ecosystems. Science, 494-499.
Santos, J. S., \& Et al. (2018). Delimitation of ecological corridors in the Brazilian Atlantic Forest. Ecological Indicators, 414-424.

Saunders, D. A., \& Hobbs, R. J. (1991). Nature Conservation 2: the Role of Corridors. Chipping Norton: Surrey Beatty \& Sons.

Simberloff, D., \& Cox, J. (1987). Consequences and Costs of Conservation Corridors. Conservation Biology .

Toro, M. A., \& Caballero, A. (2005). Characterization and conservation of genetic diversity in subdivided populations. Biological Science, 1367-1378.

Walker, R., \& Craighead, L. (1997). Analyzing wildlife movement corridors in Montana using GIS. California: ESRI User Conference Proceedings.

Xiaojun, W. (2011). Strategies of road planning based on ecological conservation. Ecological Environmental Science, 589-594.

Zhu, Q., \& Et al. (2005). The width of ecological corridor in landscape planning. Acta Ecologica Sinica . 